\title{
Transepithelial Collagen Cross-linking versus Contact Lens-assisted Collagen Cross-linking for Progressive Keratoconus with Borderline Corneal Thickness: A Prospective Comparative Study
}

\author{
${ }^{1}$ Chintan Malhotra, ${ }^{2}$ Balamurugan Ramatchandirane, ${ }^{3}$ Arun K Jain, ${ }^{4}$ Amit Gupta, ${ }^{5}$ Jagat Ram, ${ }^{6}$ Deepika Dhingra
}

\begin{abstract}
Aim: To compare outcomes of transepithelial collagen crosslinking (TECXL) and contact lens-assisted collagen crosslinking $(C A C X L)$ for progressive keratoconus with borderline corneal thickness.

Materials and methods: In this prospective, comparative, interventional series, twenty eyes with progressive keratoconus and a preoperative 'epithelium on' minimal corneal thickness (MCT) of 350-420 $\mu \mathrm{m}$, were randomized to undergo TECXL ( $=11$ eyes) or CACXL ( $\mathrm{n}=9$ eyes) using hydroxypropyl methylcellulose (HPMC) based $0.25 \%$ and $0.1 \%$ riboflavin respectively. Primary outcomes evaluated were demarcation line depth on anterior segment optical coherence tomography (ASOCT) 1 month postoperatively: change in maximum keratometry $\left(\mathrm{K}_{\max }\right)$ and endothelial cell density (ECD) at 6 months from baseline. Postoperative pain in the first 4 days and haze at 6 months were also compared between the two techniques.
\end{abstract}

Results: Preoperative 'epithelium on' MCT in the TECXL (394.3 $\pm 12.6 \mu \mathrm{m})$ and $\mathrm{CACXL}(385.6 \pm 13.8 \mu \mathrm{m})$ groups was comparable $(p=0.15)$; mean demarcation line depth was $74.6 \%(294.4$ $\pm 57.1 \mu \mathrm{m})$ and $80 \%(308.2 \pm 84.2 \mu \mathrm{m})$ respectively $(p=0.66)$. Regression (reduction of $\mathrm{K}_{\max }$ by $>1$ diopter) or stabilization (change in $K_{\max }$ of $< \pm 1 D$ ) was seen in $91 \%(n=10)$ and $89 \%$ $(\mathrm{n}=8)$ eyes of the TECXL and CACXL groups, respectively. ECD at baseline and last follow up was comparable in each group $(p>0.05)$. Postoperative pain in the first four days and haze at 6 months post the CXL procedure were also comparable (all $p$ 's $>0.05$ ).

Conclusion: Using HPMC riboflavin, both TECXL and CACXL had good clinical efficacy and equivalent patient comfort without compromising endothelial safety, in keratoconus patients with thin corneas.

Clinical significance: TECXL and CACXL are simple, costeffective techniques to arrest progression in keratoconus patients with borderline corneal thickness and may decrease

\footnotetext{
${ }^{1}$ Additional Professor, ${ }^{2}$ Senior Resident, ${ }^{3-6}$ Professor

${ }^{1-6}$ Department of Ophthalmology, Advanced Eye Centre, Postgraduate Institute of Medical Education and Research, Chandigarh, India
}

Corresponding Author: Chintan Malhotra, Additional Professor, Department of Ophthalmology, Advanced Eye Centre, Postgraduate Institute of Medical Education and Research, Chandigarh, India, e-mail: drchintansingh@yahoo.co.in the need for future surgical interventions like lamellar or penetrating keratoplasty.

Keywords: Cornea, Corneal collagen crosslinking, Ectasia, Keratoconus, Riboflavin.

How to cite this article: Malhotra $C$, Ramatchandirane $B$, Jain AK, Gupta A, Ram J, Dhingra D. Transepithelial Collagen Cross-linking versus Contact Lens-assisted Collagen Crosslinking for Progressive Keratoconus with Borderline Corneal Thickness: A Prospective Comparative Study. Int J Kerat Ect Cor Dis 2018;7(2):96-104.

Source of support: Nil

Conflict of interest: None

\section{INTRODUCTION}

Corneal collagen cross-linking (CXL) which uses riboflavin (vitamin $\mathrm{B}_{2}$ ) and ultraviolet A (UVA) light at a wavelength of $370 \mathrm{~nm}$, to increase the biomechanical and biochemical stability of the cornea is the standard of care for treatment of progressive keratoconus, with a reported efficacy of approximately $92 \% .^{1,2}$ Conventional CXL is done after removing the lipophilic corneal epithelium, which if intact hinders penetration of the hydrophilic, high molecular weight riboflavin molecule. ${ }^{3}$ To ensure that the treatment targets only the intended site, i.e., the corneal stroma, and does not have a deleterious effect on the corneal endothelium or the deeper ocular tissues, a minimal corneal thickness (MCT) of $400 \mu \mathrm{m}$ after epithelial debridement is recommended as this limits the irradiance of UVA at the endothelium to $0.18 \mathrm{~mW} / \mathrm{cm}^{2}$, which is at least a factor of two smaller than the damage threshold of $0.35 \mathrm{~mW} / \mathrm{cm}^{2}{ }^{4}$ With the limiting factor for performing CXL in thin corneas being lack of sufficient corneal stroma to absorb and attenuate the UVA irradiance before it reaches the endothelium, various modalities have been tried to maintain or artificially increase the corneal thickness during the procedure. These include the use of a hypoosmolar riboflavin solution to swell the de-epithelialized cornea, ${ }^{5}$ augmentations of corneal thickness using a cryopreserved stromal lenticule, ${ }^{6}$ iontophoresis assisted CXL, ${ }^{7}$ TECXL, ${ }^{8-10}$ and CACXL. ${ }^{11}$

TECXL utilizes a specially formulated riboflavin solution, containing substances which enhance riboflavin 
penetration across an intact corneal epithelium by loosening the intercellular tight junctions, e.g., sodium ethylene diamine tetraacetic acid (EDTA) $0.01 \%$, trometamol or benzalkonium chloride. It is done as an 'epithelium-on' procedure, avoiding the loss of thickness which occurs when the corneal epithelium is removed. This makes it a viable option for treating corneas with borderline thickness with the possible advantages of less postoperative pain, reduced risk of infectious keratitis and stromal haze, and an early return to contact lens wear. ${ }^{8,9}$ However concerns exist about the efficacy of TECXL with Wollensak et al. ${ }^{12}$ in an experimental study having demonstrated only a $21.5 \%$ increase of biomechanical rigidity with TECXL vis-a-vis $102.5 \%$ with conventional 'epithelium off ' CXL. CACXL, on the other hand, is an 'epithelium off' technique utilizing a riboflavin soaked, ultraviolet light barrier free soft contact lens to temporarily augment stromal thickness and has been proposed by Jacob et al., ${ }^{11}$ as a simple and efficacious alternative to cross-link thin corneas. Unlike CXL with a hypoosmolar riboflavin solution, both TECXL and CACXL are not dependant on the corneal stromal swelling properties. Additionally, both are relatively simple techniques not requiring any additional equipment or biological tissue as required for iontophoresis assisted CXL and CXL performed using a cryopreserved stromal lenticule respectively.

Keratoconus patients with 'epithelium on' MCT less than $400 \mu \mathrm{m}$ ('thin corneas') or those with borderline corneal thickness, i.e., 'epithelium on $\mathrm{MCT}^{\prime} \geq 400 \mu \mathrm{m}$ but expected to fall below the safety limit of $400 \mu \mathrm{m}$ after epithelial removal may often be considered ineligible for conventional 'epithelium off' CXL. Since this subset of patients may account for a significant proportion of those suffering from progressive disease, the present study was planned to compare the clinical outcomes, safety and efficacy of TECXL and CACXL in a homogenous subset of patients having progressive keratoconus and 'epithelium on' minimal corneal thickness (MCT) between $350 \mu \mathrm{m}$ and $420 \mu \mathrm{m}$.

\section{MATERIALS AND METHODS}

This prospective, comparative, randomized, interventional study was carried out over a duration of 1.5 years at the cornea services of a tertiary care institute in North India. The study adhered to the tenets of the Declaration of Helsinki and was cleared by the institutional review board. Twenty consecutive patients having progressive keratoconus ${ }^{11,13}$ and 'epithelium on' MCT between $350 \mu \mathrm{m}$ and $420 \mu \mathrm{m}$ in the eye to be cross-linked, were recruited. For patients having bilateral disease requiring CXL, the eye with the more severe disease was included in the study. Patients using contact lenses were asked to discontinue use for a minimum of two weeks for soft lenses and 4 weeks for rigid gas permeable lenses, prior to recruitment in the study. Patients were randomized into those undergoing TECXL or CACXL based on a random number table. Informed consent was obtained from all individual participants included in the study.

\section{Inclusion and Exclusion Criteria}

Inclusion criteria were patients 12 years or older with (i) grades II-III keratoconus according to the Krumeich classification, ${ }^{14}$ (ii) maximum keratometric value $\left(\mathrm{K}_{\max }\right)$ $\leq 69 \mathrm{D}$ (iii) preoperative 'epithelium on' $\mathrm{MCT} \geq 350 \mu \mathrm{m}$ and $\leq 420 \mu \mathrm{m}$ on Scheimpflug imaging (iv) Snellen spectaclecorrected distance visual acuity (CDVA) worse than 20/20 (v) endothelial cell density (ECD) $\geq 2000$ cells $/ \mathrm{mm}^{2}$ (vi) minimal follow-up duration of 6 months after CXL.

Exclusion criteria were (i) presence of corneal opacity or scarring (ii) active ocular infection (iii) active vernal keratoconjunctivitis or other forms of allergic eye disease (iii) history of recurrent corneal erosions (iv) previous episodes of herpetic keratitis (v) connective tissue disorders (vi) pregnancy (vii) lactation (viii) diabetes (ix) dry eye syndrome $(x)$ previous history of crosslinking in the eye to be treated.

A thorough anterior and posterior segment examination was done preoperatively, with Snellen's spectacle CDVA and refraction including sphere, cylinder and manifest refractive spherical equivalent (MRSE) being noted at baseline. Corneal topography and pachymetry using Scheimpflug imaging with the Pentacam (Oculus Optikgerate $\mathrm{GmbH}$, Wetzlar, Germany), corneal biomechanics [cornea resistance factor (CRF) and corneal hysteresis $(\mathrm{CH})]$ with ocular response analyzer (ORA; Reichert Inc, Depew, NY), anterior segment optical coherence tomography (ASOCT, Heidelberg Engineering $\mathrm{GmbH}$, Heidelberg, Germany) and ECD using the modified confocal scanning laser ophthalmoscope (Heidelberg Retina Tomograph-3 with Rostock Cornea Module, Heidelberg Engineering, $\mathrm{GmbH}$, Dossenheim, Germany) were also performed before any patient was taken up for the CXL procedure. For mean ECD measurements, a m inimum of 50 cells were marked manually in the chosen image using the semiautomated software available with the machine to reduce error.

\section{Surgical Technique}

Moxifloxacin $0.5 \%$ was used for preoperative prophylaxis one day before surgery. Pupillary miosis was ensured with $2 \%$ pilocarpine eye drops instilled twice, an hour before the patient was shifted to the operating theatre. Following instillation of $0.5 \%$ proparacaine (one drop each, thrice at 5-minute intervals) to achieve topical anesthesia, the thinnest point of the cornea (estimated from 
the pachymetry map of the Pentacam) was marked with a sterile surgical marking pen in all patients. Ultrasonic pachymetry was performed at this point with a $20 \mathrm{MHz}$ handheld pachymeter (SP-100 Handheld Pachymeter, Tomey, CBD Tomey, USA) in both groups.

\section{TECXL Group}

Following the initial steps, one drop of riboflavin $0.25 \%$ solution in $1.2 \%$ hydroxyl propyl methyl cellulose (HPMC) and containing $0.01 \%$ benzalkonium chloride (PESCHKE TE, Peschke Trade GmbH, Huenenberg, Switzerland) was instilled every 3 minutes for the first 30 minutes following which ultrasonic pachymetry was repeated at the thinnest point. The patient was then examined on a slit lamp to look for a green flare in the anterior chamber which confirmed penetration of riboflavin through the corneal layers and hence adequate saturation of the corneal stroma. Next, the central $8 \mathrm{~mm}$ of the cornea was exposed for 30 minutes to UVA (365 nm) irradiation using the costruzione strumenti oftalmici (CSO) Vega at an irradiance level of $3.0 \mathrm{~mW} / \mathrm{cm}^{2}$. During UVA irradiation, riboflavin drops were continued every 3 minutes throughout the 30-minute duration. At the end of the procedure, the eye was rinsed with a balanced salt solution (BSS).

\section{CACXL Group}

Following the initial steps, the central $8.5 \mathrm{~mm}$ of epithelium was removed by mechanical debridement. The previously marked thinnest corneal point was remarked on the corneal stroma, and pachymetry repeated to obtain the postabrasion minimum corneal thickness. One drop of iso-osmolar riboflavin $0.1 \%$ solution in 1.1\% HPMC (PESCHKE M, Peschke Trade GmbH, Huenenberg, Switzerland) was instilled every 3 minutes for the first 30 minutes. Simultaneously, as described by Jacob et al., ${ }^{11}$ a daily disposable, UV barrier-free, a soft contact lens made of hilafilcon B, $0.09 \mathrm{~mm}$ in thickness and having an overall diameter of $14.2 \mathrm{~mm}$ (Soflens 59, Bausch and Lomb) was immersed in the iso-osmolar riboflavin for 30 minutes. At the end of the first 30 minutes, pachymetry of the deepithelialized, riboflavin soaked cornea was repeated at the thinnest point. Slit lamp examination with a cobalt blue filter was then carried out to determine the presence of a green flare in the anterior chamber. The riboflavin-soaked contact lens was then placed on the corneal surface and thickness of the complex consisting of contact lens, precorneal riboflavin film, and underlying corneal stroma (at the previously marked thinnest point) remeasured. Next, the central $8 \mathrm{~mm}$ of the cornea was exposed for 30 minutes to UVA ( $365 \mathrm{~nm}$ ) irradiation using the CSO vega cross linking device at an irradiance level of $3.0 \mathrm{~mW} / \mathrm{cm}^{2}$. Instillation of riboflavin drops was continued every 3 minutes both under and over the contact lens for the 30-minute duration of UVA irradiance, to maintain the corneal saturation, keep the precorneal and precontact lens riboflavin film uniform and avoid drying or buckling of any part of the contact lens. At the end of the procedure, the riboflavin soaked contact was replaced by a silicone hydrogel bandage contact lens (BCL) after thoroughly rinsing the ocular surface with BSS.

Postoperatively, all patients were prescribed topical moxifloxacin $0.5 \%$, four times/day for one week, fluorometholone $0.1 \%$ four times/day initially tapered over three weeks, and lubricant drops six times/day for three months.

\section{Postoperative Evaluation}

On the first postoperative day, patients in the TECXL group were specifically examined for the presence of any frank epithelial defects and if present a BCL was applied. The BCL was removed after complete healing of the epithelial defect in all patients of the CACXL group and those of the TECXL group in whom it had been inserted on the first postoperative day. To assess postoperative pain on the day of surgery and for four days after that, patients were given a self-report structured questionnaire, based on the Wong-Baker faces pain rating scale ${ }^{15}$ with instructions to rate scores corresponding to the pain level felt throughout the entire day. The pain rating scale was graded from $0-5$, i.e., $0=$ no hurt (no pain); $1=$ hurts little bit (discomfort), 2 = hurts little more (light pain); $3=$ hurts even more (moderate pain); $4=$ hurts whole lot (intense pain); 5 = hurts worst (unbearable pain).

On all subsequent visits, i.e., the 1st, 3rd and 6th month visits, in addition to assessment of spectacle CDVA, manifest refraction, Schiempflug imaging and ORA, the degree of stromal haze present was graded clinically on slit lamp biomicroscopy on a scale from 0 to $4: 0+=$ clear cornea; $1+=$ focal areas of minimal stromal clouding or reticulation; $2+=$ diffuse mild stromal clouding or reticulation; $3+=$ diffuse stromal clouding or reticulation somewhat obscuring view of iris details; $4+=$ focal or diffuse areas of dense stromal haze obscuring iris detail. ${ }^{13}$ ASOCT was repeated 1 month after CXL to note the appearance and depth of the demarcation line as described previously. ${ }^{16}$ Briefly, the depth of the demarcation line (visible as a hyperreflective line in the corneal stroma) was measured at five points including the centre and $1.5 \mathrm{~mm}$ and $3 \mathrm{~mm}$ nasal and temporal to the centrally measured location (Fig. 1). Values at the five locations were averaged to determine the mean demarcation line depth in each group. Confocal microscopy was repeated at the 6th month visit to determine any change in ECD from baseline. 


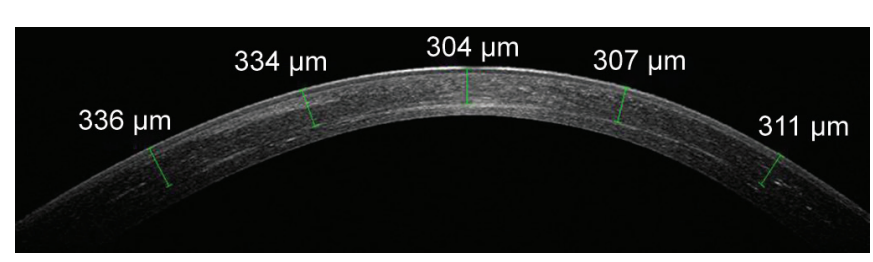

Fig. 1: Measurement of the demarcation line with anterior segment optical coherence tomography at five points including the corneal apex and $1.5 \mathrm{~mm}$ and $3 \mathrm{~mm}$ nasal and temporal to the centrally measured location The demarcation line appears as a hyperreflective line in the stroma

\section{Outcome Measures}

Primary outcome measures evaluated were (a) change in $\mathrm{K}_{\max }$ as an indicator of the ability of the particular CXL procedure to halt the ectatic process, with regression being defined as decrease of $K_{\max }$ by $\geq-1 D$, stabilization as $K_{\max }$ value within $\pm 1 \mathrm{D}$ value from baseline and progression as increase of $K_{\max } \geq 1 \mathrm{D}$ from the baseline value, ${ }^{5}$ (b) mean demarcation line depth measured 1 month postoperatively on ASOCT, as a surrogate measure of the extent of effective crosslinking with each technique (c) change in mean ECD from baseline to last follow-up in each group, as a reflection of endothelial safety of the technique.

Secondary outcome measures were changed from baseline in visual function (spectacle CDVA), manifest refraction (MRSE) and corneal biomechanics (CRF and $\mathrm{CH}$ ) on ORA, with both within and between group comparisons being made. Additionally, intraoperative pachymetric changes, postoperative pain scores, and postoperative corneal haze were also compared between the two groups.

The normality of quantitative data was checked by measures of Kolmogorov-Smirnov tests of normality. For normally distributed measurable data, Student's t-test was applied to compare the two group means. Mann-Whitney U-test was used for statistical analysis of skewed continuous variables or ordered categorical data. Proportions were compared using Chi-square or Fisher's exact test, depending on their applicability. Both intra- and inter-group comparisons were made. To see the relationship between different variables Spearman or Pearson correlation coefficient was applied. All the statistical tests were two-sided and performed at a significance level of $=0.05$. A $p$ value of $<0.05$ was considered significant. The analysis was conducted using IBM statistical package for the social sciences (SPSS) statistics (version 22.0, Chicago, IL, USA).

\section{RESULTS}

Twenty eyes (from 20 patients) were included in this study with 11 eyes being randomized to the TECXL group (nine males, two females) and nine eyes to the CACXL group (six males, three females). We have partially reported data of the nine patients belonging to the CACXL group in a previous study retrospectively comparing outcomes of CACXL performed using either a dextranbased or HPMC based riboflavin formulation. ${ }^{16}$ In the present study mean age was comparable being $19.9 \pm 4.7$ years (range 13-29 years) and $18.4 \pm 4.3$ years (range 13-24 years) for the TECXL and CACXL groups respectively $(p=0.48)$ The mean follow-up duration of $282.2 \pm 56.5$ days (range 184-374 days) in the TECXL group and 240.2 \pm 54.9 days (range 189-308 days) in CACXL group was also comparable $(p=0.11)$. As shown in Table 1 , the groups were similar with respect to baseline visual, refractive, keratometric and biomechanical parameters, as well as the mean ECD.

\section{Primary Outcome Measures}

\section{Changes in Keratometric Parameters}

On comparing the two groups, mean simulated flat and steep keratometry (flat $\mathrm{K}$ and steep $\mathrm{K}$, respectively) and simulated keratometry average $\left(\mathrm{K}_{\mathrm{m}}\right)$ were comparable at both baselines and last follow-up (Table 1). Withingroup comparison showed a significant decrease of mean flat $\mathrm{K}(p=0.009)$ in the TECXL subset and mean flat $\mathrm{K}$ $(p=0.004)$, steep $\mathrm{K}(p=0.003)$ and $\mathrm{K}_{\mathrm{m}}(p=0.001)$ values in the CACXL subset. Mean $\mathrm{K}$ max reduced in both groups after CXL though the difference did not reach statistical significance in either group (Table 1). However, when evaluated individually, in the TECXL group 4 eyes $(36.4 \%)$ showed regression, i.e., decrease in $K_{\max } \geq 1 \mathrm{D}$, six eyes (54.5\%) were stable, i.e., change in $\mathrm{K}_{\max }<1 \mathrm{D}$ and one patient (9.1\%) progressed, i.e., increase in $K_{\max } \geq 1 \mathrm{D}$. In the CACXL group regression was documented in 5 eyes $(55.6 \%)$, stabilization in $3(33.3 \%)$ and progression in 1 eye (11.1\%) (Table 2). Failure rate (number of eyes showing progression/total number of eyes treated) was $9.1 \%$ and $11.1 \%$, respectively in the TECXL and CACXL groups, respectively.

\section{Demarcation Line Depth on ASOCT}

Baseline pachymetry on Scheimpflug imaging was comparable, being $394.3 \pm 12.6 \mu \mathrm{m}$ (range 366-417 $\mu \mathrm{m}$ ) in the TECXL group and $385.6 \pm 13.8 \mu \mathrm{m}$ (range 362-405 $\mu \mathrm{m}$ ) in the CACXL groups $(p=0.15)$. The demarcation line occurred at a mean depth of $294.4 \pm 57.1 \mu \mathrm{m}$ and 308.2 $\pm 84.2 \mu \mathrm{m}$ in the TECXL group and CACXL group respectively. The mean depth of the demarcation line between the two groups was comparable $(p=0.66)$, as was the mean depth at each of the 5 locations measured (all $\left.p^{\prime} \mathrm{s}>0.05\right)$ (Graph 1). 
Table 1 : Within group and between group comparison of parameters before (pre) and $\geq 6$ months after( post) collagen crosslinking

\begin{tabular}{|c|c|c|c|c|c|c|c|c|}
\hline \multirow[b]{2}{*}{ Parameter } & \multicolumn{2}{|c|}{$\begin{array}{c}\text { TECXL group } \\
\text { ( } n=11 \text { eyes) } \\
\text { Mean } \pm S D \\
\text { (range) }\end{array}$} & \multirow{2}{*}{$\begin{array}{l}\text { Within } \\
\text { group } p \\
\text { value }\end{array}$} & \multicolumn{2}{|c|}{$\begin{array}{l}\text { CACXL group } \\
\text { ( } n=9 \text { eyes) } \\
\text { Mean } \pm S D \\
\text { (range) }\end{array}$} & \multirow{2}{*}{$\begin{array}{l}\text { Within } \\
\text { group } p \\
\text { value }\end{array}$} & \multirow[t]{2}{*}{$\begin{array}{l}\text { Between } \\
\text { group } \\
\text { p value } \\
\text { Pre-CXL }\end{array}$} & \multirow{2}{*}{$\begin{array}{l}\text { Between } \\
\text { group } \\
\text { p value } \\
\text { Post-CXL }\end{array}$} \\
\hline & Pre-CXL & Post-CXL & & Pre-CXL & Post-CXL & & & \\
\hline $\begin{array}{l}\text { Steep K } \\
\text { (D) }\end{array}$ & $\begin{array}{l}54.82 \pm 4.20 \\
(48.0-62.1)\end{array}$ & $\begin{array}{l}54.31 \pm 3.91 \\
(48.4-62)\end{array}$ & 0.17 & $\begin{array}{l}57.27 \pm 2.76 \\
(53.0-61.8)\end{array}$ & $\begin{array}{l}56.17 \pm 2.94 \\
(50.6-60.7)\end{array}$ & $0.003^{*}$ & 0.15 & 0.26 \\
\hline $\begin{array}{l}\text { Flat K } \\
\text { (D) }\end{array}$ & $\begin{array}{l}50.93 \pm 3.24 \\
(46.0-56.0)\end{array}$ & $\begin{array}{l}50.33 \pm 3.02 \\
(44.8-55.5)\end{array}$ & $0.009^{*}$ & $\begin{array}{l}52.65 \pm 3.21 \\
(46.7-56.5)\end{array}$ & $\begin{array}{l}51.32 \pm 2.72 \\
(45.6-54.3)\end{array}$ & $0.004^{*}$ & 0.25 & 0.45 \\
\hline $\begin{array}{l}\mathrm{K}_{\mathrm{m}} \\
(\mathrm{D})\end{array}$ & $\begin{array}{l}52.8 \pm 3.65 \\
(47-58.9)\end{array}$ & $\begin{array}{l}52.24 \pm 3.38 \\
(46.5-58.6)\end{array}$ & 0.05 & $\begin{array}{l}54.86 \pm 2.73 \\
(49.7-58.3)\end{array}$ & $\begin{array}{l}53.61 \pm 2.59 \\
(47.9-56.3)\end{array}$ & $0.001^{*}$ & 0.17 & 0.34 \\
\hline $\begin{array}{l}\mathrm{K} \text { max } \\
\text { (D) }\end{array}$ & $\begin{array}{l}61.16 \pm 4.31 \\
(53.9-68.6)\end{array}$ & $\begin{array}{l}60.49 \pm 4.47 \\
(52.5-67.4)\end{array}$ & 0.27 & $\begin{array}{l}63.48 \pm 3.17 \\
(57.1-67.2)\end{array}$ & $\begin{array}{l}62.01 \pm 3.07 \\
(56.1-67.0)\end{array}$ & 0.10 & 0.20 & 0.40 \\
\hline $\begin{array}{l}\text { Spectacle } \\
\text { CDVA } \\
\text { (logMAR) }\end{array}$ & $\begin{array}{l}0.42 \pm 0.16 \\
(0.3-0.78)\end{array}$ & $\begin{array}{l}0.40 \pm 0.25 \\
(0.18-1.0)\end{array}$ & 0.71 & $\begin{array}{l}0.56 \pm 0.19 \\
(0.18-0.78)\end{array}$ & $\begin{array}{l}0.51 \pm 0.18 \\
(0.18-0.78)\end{array}$ & 0.26 & 0.09 & 0.28 \\
\hline $\begin{array}{l}\text { Sphere } \\
\text { (D) }\end{array}$ & $\begin{array}{l}-3.66 \pm 3.97 \\
(0--12 D)\end{array}$ & $\begin{array}{l}-2.68 \pm 3.33 \\
(0.25--11.0)\end{array}$ & 0.31 & $\begin{array}{l}-3.92 \pm 3.21 \\
(0.75 \mathrm{D}-6.25 \mathrm{D})\end{array}$ & $\begin{array}{l}-2.77 \pm 2.26 \\
(-0.75--6.5)\end{array}$ & 0.21 & 0.88 & 0.94 \\
\hline $\begin{array}{l}\text { Cylinder } \\
\text { (D) }\end{array}$ & $\begin{array}{l}-3.36 \pm 1.23 \\
(-2--5.5)\end{array}$ & $\begin{array}{l}-2.95 \pm 1.42 \\
(-1.0--5.5)\end{array}$ & 0.15 & $\begin{array}{l}-3.75 \pm 1.20 \\
(-1.75--5.5)\end{array}$ & $\begin{array}{l}-3.86 \pm 1.03 \\
(-2.5--5.5)\end{array}$ & 0.80 & 0.49 & 0.13 \\
\hline $\begin{array}{l}\text { MRSE } \\
\text { (D) }\end{array}$ & $\begin{array}{l}-5.34 \pm 4.43 \\
(-1--14.5)\end{array}$ & $\begin{array}{l}-4.16 \pm 3.52 \\
(-1.0--12.25)\end{array}$ & 0.22 & $\begin{array}{l}-5.79 \pm 3.69 \\
(-0.75--9.75)\end{array}$ & $\begin{array}{l}-4.65 \pm 2.47 \\
(-2.5--8.25)\end{array}$ & 0.26 & 0.81 & 0.73 \\
\hline $\begin{array}{l}\text { ECD } \\
\left(\text { cells } / \mathrm{mm}^{2}\right)\end{array}$ & $\begin{array}{l}2893 \pm 354 \\
(2425-3444)\end{array}$ & $\begin{array}{l}2918 \pm 275 \\
(2587-3372)\end{array}$ & 0.63 & $\begin{array}{l}2883 \pm 260 \\
(2505-3344)\end{array}$ & $\begin{array}{l}2810 \pm 365 \\
(2039-3292)\end{array}$ & 0.53 & 0.94 & 0.46 \\
\hline $\begin{array}{l}\text { CRF } \\
(\mathrm{mm} \mathrm{Hg})\end{array}$ & $\begin{array}{l}5.1 \pm 1.1 \\
(3.7-6.7)\end{array}$ & $\begin{array}{l}6.4 \pm 1.6 \\
(4.9-10.5)\end{array}$ & $0.04^{*}$ & $\begin{array}{l}4.4 \pm 1.5 \\
(2.6-6.4)\end{array}$ & $\begin{array}{l}5.0 \pm 1.4 \\
(2.5-6.7)\end{array}$ & 0.35 & 0.20 & $0.04^{*}$ \\
\hline $\begin{array}{l}\mathrm{CH} \\
(\mathrm{mm} \mathrm{Hg})\end{array}$ & $\begin{array}{l}6.8 \pm 1.1 \\
(5.3-8.7)\end{array}$ & $\begin{array}{l}8.0 \pm 2.1 \\
(5.8-13.8)\end{array}$ & 0.15 & $\begin{array}{l}6.0 \pm 1.0 \\
(4.2-7.6)\end{array}$ & $\begin{array}{l}6.9 \pm 1.6 \\
(4.9-10.3)\end{array}$ & 0.20 & 0.13 & 0.19 \\
\hline
\end{tabular}

CACXL, contact lens assisted collagen crosslinking; CDVA, spectacle corrected distant visual acuity; $\mathrm{CH}$, corneal hysteresis; CRF, cornea resistance factor; CXL, collagen cross linking; D, Diopter; ECD, endothelial cell density; 'epi on' MCT, Epithelium on' minimal corneal thickness; Flat $\mathrm{K}$, simulated flat keratometry; $\mathrm{K}_{\mathrm{m}}$, simulated keratometry average; $\mathrm{K}_{\max }$, maximum keratometric value; logMAR, logarithmic minimum angle of resolution; MRSE, manifest refractive spherical equivalent; SD, standard deviation; Steep K, simulated steep keratometry; TECXL, transepithelial collagen crosslinking; ${ }^{*}$ Significant $p$ value $(p<0.05)$

Table 2: Comparison of $\mathrm{K}_{\max }$ values pre- and post-collagen crosslinking

\begin{tabular}{|c|c|c|c|c|c|c|}
\hline \multirow[b]{2}{*}{ S. no } & \multicolumn{2}{|c|}{$\begin{array}{l}\text { TECXL group } \\
(n=11 \text { eyes }) \\
K_{\max }(D)\end{array}$} & \multirow{2}{*}{$\begin{array}{l}\text { Outcome } \\
\text { (progression/stabilization/ } \\
\text { regression) }\end{array}$} & \multicolumn{2}{|c|}{$\begin{array}{c}\text { CACXL group } \\
(n=9 \text { eyes) } \\
K_{\max }(D)\end{array}$} & \multirow{2}{*}{$\begin{array}{l}\text { Outcome } \\
\text { (progression/stabilization/ } \\
\text { regression) }\end{array}$} \\
\hline & Pre-CXL & Post-CXL & & Pre-CXL & Post-CXL & \\
\hline 1 & 65.8 & 63.9 & Regressed & 61.1 & 60.4 & Stabilized \\
\hline 2 & 63.6 & 63.1 & Stabilized & 67.2 & 63.9 & Regressed \\
\hline 3 & 68.6 & 67.4 & Regressed & 65.2 & 60 & Regressed \\
\hline 4 & 57.7 & 57.1 & Stabilized & 61.4 & 62 & Stabilized \\
\hline 5 & 53.9 & 52.5 & Regressed & 57.1 & 56.1 & Regressed \\
\hline 6 & 62.5 & 57.2 & Regressed & 66.1 & 61.6 & Regressed \\
\hline 7 & 63.9 & 66.1 & Progressed & 65.2 & 67 & Progressed \\
\hline 8 & 61.6 & 62.2 & Stabilized & 65.2 & 64.1 & Regressed \\
\hline 9 & 59.4 & 59 & Stabilized & 62.9 & 63 & Stabilized \\
\hline 10 & 59.5 & 59.7 & Stabilized & - & - & - \\
\hline 11 & 56.3 & 57.2 & Stabilized & - & - & - \\
\hline
\end{tabular}

CACXL, contact lens-assisted collagen crosslinking; $\mathrm{D}$, diopters; $\mathrm{K}_{\max }$, maximum keratometric value; TECXL, transepithelial collagen crosslinking, progression, increase of $\mathrm{K}_{\max }>1 \mathrm{D}$; Regression, reduction of $\mathrm{K}_{\max }>1 \mathrm{D}$; stabilization, Change of $\mathrm{K}_{\max } \leq 1 \mathrm{D}$

Endothelial cell density (ECD): The baseline ECD and ECD, at last, follow-up was comparable between the two groups ( $p=0.94$ and 0.46 , respectively), as was the pre- and post-CXL ECD in both the TECXL $(p=0.63)$ and CACXL groups $(p=0.53)$ individually (Table 1$)$.

\section{Secondary Outcome Measures}

\section{Changes in Visual and Refractive Parameters}

Overall no statistically significant change from baseline to last follow-up was noted in either group for the visual 


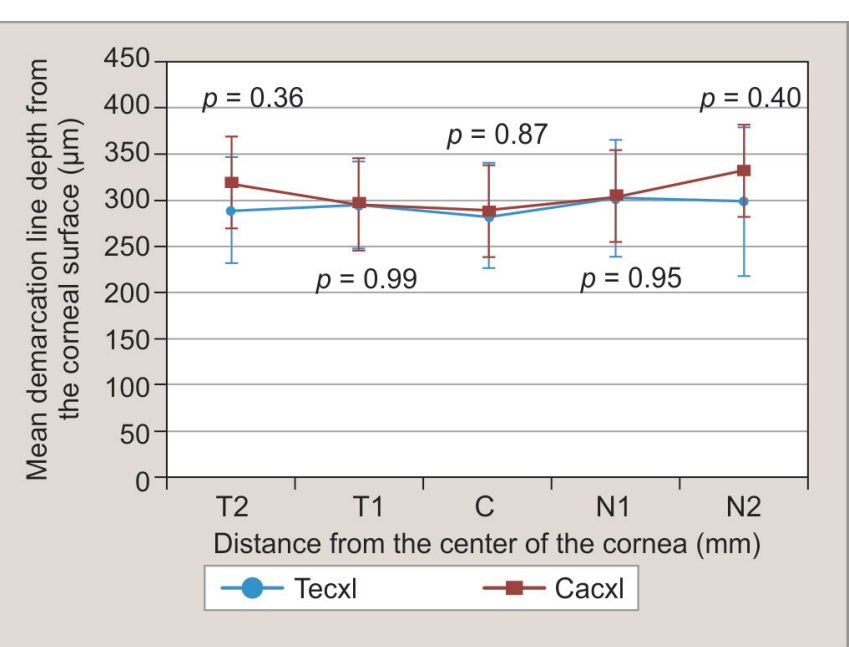

Graph 1: Line chart comparing mean demarcation line depth in both the transepithelial collagen cross-linking (TECXL) and contact lens-assisted collagen cross-linking (CACXL) groups at the 5 specified locations. $\mathrm{C}=$ corneal apex; $\mathrm{T} 1$ and $\mathrm{T} 2=1.5 \mathrm{~mm}$ and $3 \mathrm{~mm}$ temporal to corneal apex respectively; $\mathrm{N} 1$ and $\mathrm{N} 2=1.5 \mathrm{~mm}$ and $3 \mathrm{~mm}$ nasal to corneal apex respectively

and refractive parameters, i.e., mean spectacle CDVA, sphere, cylinder and manifest refractive spherical equivalent (MRSE), though a trend towards improvement was present for most variables (Table 1). Graph 2 depicts the postoperative change in Snellen's spectacle CDVA for all eyes in both groups. Both procedures were equally safe with a safety index (mean decimal equivalent postoperative CDVA/mean decimal equivalent preoperative CDVA of 1.1 .

\section{Changes in Corneal Biomechanics on ORA}

As shown in Table 1, mean CRF and $\mathrm{CH}$ increased in both the groups after CXL, though on within-group comparison from baseline to last follow up, the difference reached statistical significance $(p=0.04)$ only for CRF in the TECXL group. This increase was also reflected in

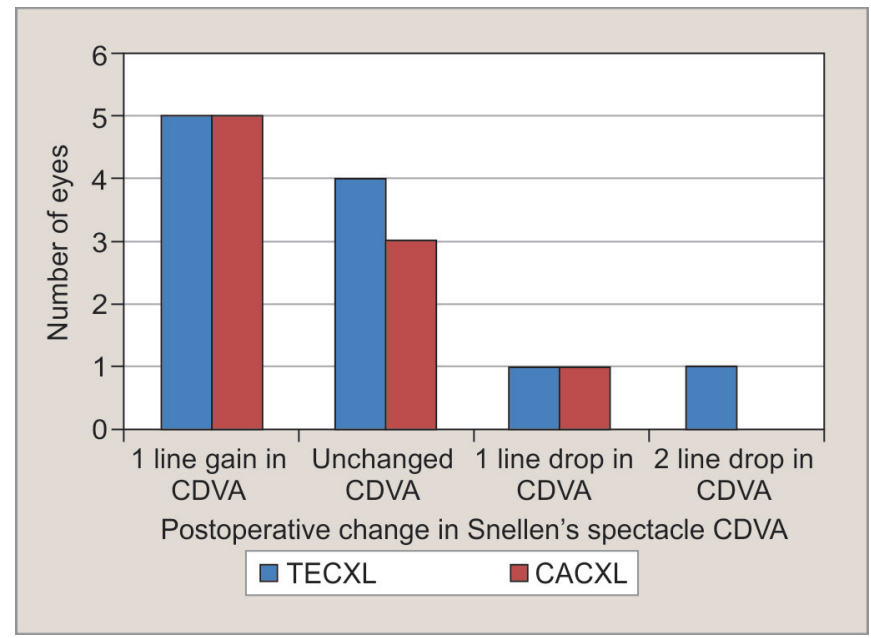

Graph 2: Change in Snellens spectacle corrected distance visual acuity $=6$ months after the patients underwent transepithelial collagen cross-linking or contact lens-assisted collagen cross-linking
CRF of the TECXL group post CXL $(6.4 \pm 1.6 \mathrm{~mm} \mathrm{Hg})$, being significantly higher than that in the CACXL group $(5.0 \pm 1.4 \mathrm{~mm} \mathrm{Hg})(p=0.04)$.

Postoperative pain scores: Mean pain scores for the CACXL group were higher than those for the TECXL group at all time points in the early postoperative period, though the difference did not reach statistical significance (all $p$ 's > 0.05) (Graph 3). The pain scores decreased progressively for both groups from day 0 to day 3 with all patients in both groups being pain-free by day 4 .

Postoperative corneal haze: Mean scores for corneal haze were comparable in both the groups at the 1st, 3rd and 6th months follow up visits post-CXL (all $p$ values $>0.05$ ) (Graph 4). Individually seen at the 6-month visit grade one and two haze was observed in five eyes each (45.5\% each) in the TECXL group, with one eye having no clinically detectable haze (grade 0 ), and no eye developing a grade three haze. In the CACXL group at the 6th month

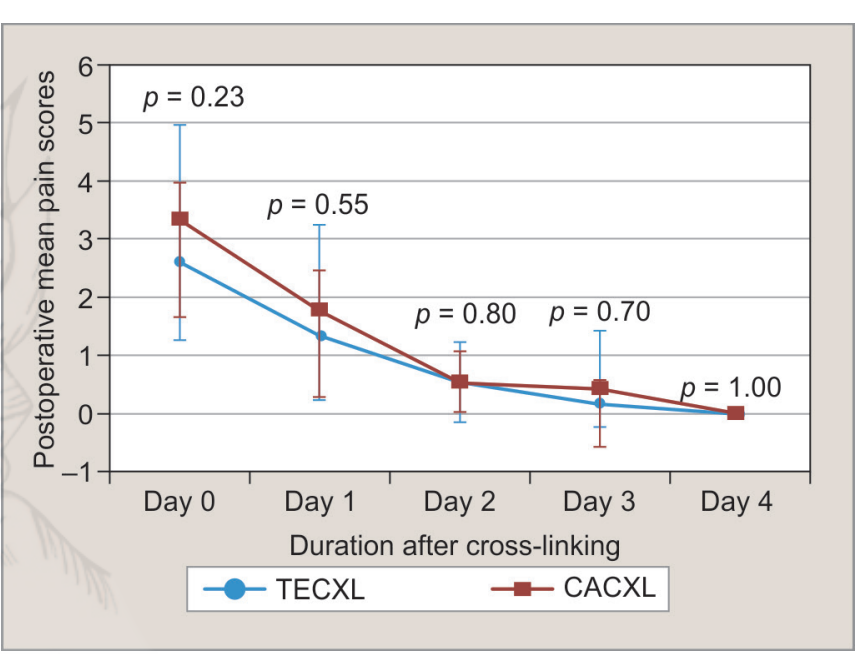

Graph 3: Line chart comparing mean pain scores on the day of surgery (day 0 ) and in the next four postoperative days after the patients underwent transepithelial collagen cross-linking or contact lens-assisted collagen cross-linking

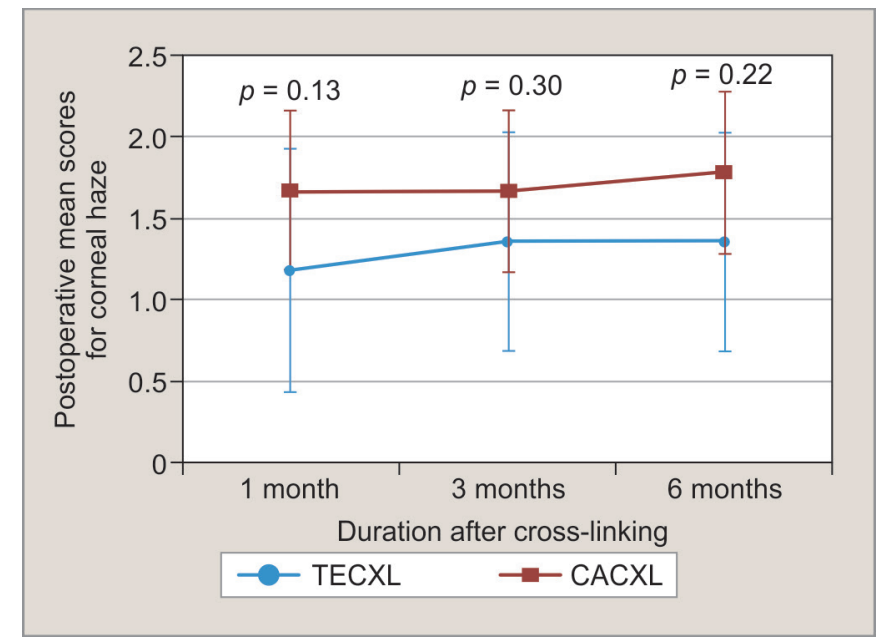

Graph 4: Line chart comparing postoperative mean scores for corneal haze after the patients underwent transepithelial collagen cross-linking or contact lens-assisted collagen cross-linking 
visit post-CXL, persistent grade one and two haze was seen in three (33.3\%) and five (55.6\%) eyes respectively, while one eye which had developed a grade 3 haze at the 3 month visit, was noted to have developed a faint anterior stromal scar at the last follow-up. This patient however, maintained the preoperative CDVA, despite the presence of the corneal scar.

Epithelial defects: All 9 eyes in the CACXL group (100\%) had an epithelial defect on the first postoperative day while in the TECXL group 5 out of 11 eyes (45.5\%) had corneal epithelial disturbances on the first postoperative day either in the form of epithelial defects $(n=3)$ for which a BCL was inserted or loose epithelium with marked punctuate epitheliopathy $(n=2)$. Complete healing of the epithelium was noted in both groups within 3-4 days of the CXL procedure.

\section{Intraoperative Pachymetric Changes}

In the TECXL group, there was a significant increase in corneal thickness from an initial pachymetry of $393 \pm$ $6.3 \mu \mathrm{m}$ at baseline to $415.5 \pm 10.2 \mu \mathrm{m}$ after the 30 -minute saturation phase with riboflavin $(p<0.01)$. In the CACXL group, corneal thickness reduced significantly from an initial mean MCT of $386.9 \pm 6.3 \mu \mathrm{m}$ to $360.7 \pm 5.8 \mu \mathrm{m}$ after epithelial debridement $(p<0.01)$. Following the 30-minute saturation phase with riboflavin post epithelial removal, the pachymetry increased by approximately 35 $\mu \mathrm{m}$ to $395.8 \pm 5.01 \mu \mathrm{m}(p<0.01)$. The mean overall thickness of the contact lens, pre corneal riboflavin film and underlying deepithelialized corneal stromal complex at the previously marked thinnest point of the cornea were measured to be $475 \pm 11.8 \mu \mathrm{m}$ which also was a significant increase over the post-epithelial debridement pachymetry $(p<0.01)$.

\section{DISCUSSION}

Various studies have compared TECXL with standard epithelium off CXL in patients suitable for conventional cross-linking with mixed results. ${ }^{8,17-20}$ Outcomes of TECXL in patients with thin corneas have however been reported only by a few authors, ${ }^{9,10}$ and published data about outcomes of CACXL is also limited ${ }^{11,16}$ as this technique is relatively recent. In the present study, a greater number of keratometric parameters $\left(\mathrm{K}_{\mathrm{m}}\right.$, steep $\mathrm{K}$, flat $\mathrm{K}$ ) improved significantly in the CACXL group ( $p=0.001,0.003$ and 0.004 , respectively) while in the TECXL group only flat K showed significant improvement $(p=0.009)$ other parameters remaining stable. Mean $\mathrm{K}_{\max }$ decreased by approximately $0.67 \mathrm{D}$ in the TECXL group and by nearly double (1.47D) in the CACXL group as compared to baseline.
Additionally, in both groups, there was a trend for improvement of mean logMAR spectacle CDVA and MRSE, at last, follow-up as compared to baseline though the difference was not statistically significant. Previous studies on TECXL have shown mixed results with some authors $^{10}$ showing no improvement in CDVA at 1 year, Filippello et al. ${ }^{9}$ documenting significant improvement from the 1 month postoperative period which was maintained up to 18 months and Caporossi et al. ${ }^{17}$ noting an initial improvement in the first six months followed by a return to preoperative levels by 24 months. Jacob et al. ${ }^{11}$ in their series of CACXL demonstrated a nonsignificant decrease in CDVA after a follow up of 6-7 months. Our results appear to be in tune with the findings of Cerman et al. ${ }^{19}$ who reported that 'epithelium-off' CXL (of which CACXL is a variant) may be more effective in improving keratometry values as compared to TECXL, though the effect on visual acuity was likely to be similar.

Evaluation of spectacle-corrected Snellens distance visual acuity showed a one-line improvement or stabilization in greater than $80 \%$ eyes in both groups. Additionally based on the predefined parameter of change in $\geq 1 \mathrm{D}$ increase in $\mathrm{K}_{\max }$ being considered as progression, $90.9 \%$ (10 out of 11) patients in the TECXL group and $88.9 \%$ (8 out of 9) patients in the CACXL group were either stable or showed regression. Biomechanical corneal strength as evaluated by changes in CRF and $\mathrm{CH}$ also improved marginally in both the groups. As progressive keratoconus is associated with a deteriorating corneal topography, the decrease in visual acuity/quality and reduced biomechanical strength, any variant of the CXL technique may be considered effective if it either leads to an improvement or prevents further deterioration of these parameters. Based on these outcome measures, in the present study both TECXL and CACXL seemed to be equally effective in arresting the progression of keratoconus in the short term. The lack of a statistical significance (despite a trend for clinical improvement in a majority of the patients) for some of the refractive and keratometric parameters evaluated may be attributable to small sample size as well as a relatively shorter duration of follow-up. Rossi et al. ${ }^{20}$ in their comparison of standard versus transepithelial CXL documented an improvement for most parameters in both groups, only at the 12 months follow-up visit with no significant difference being seen at the 3-month visit.

The demarcation line representing the transition zone between the anterior cross-linked and posterior untreated corneal stroma has been shown to occur at a depth of approximately $60 \%$ i.e.at $300 \mu \mathrm{m}$, in standard 'epitheliumoff 'CXL. ${ }^{21}$ Jacob et al. ${ }^{11}$ documented a mean demarcation line depth of $252.9 \pm 40.8 \mu \mathrm{m}$ in their cohort of keratoconus patients with thin corneas undergoing CACXL 
using a dextran containing riboflavin solution. We have also previously documented a mean DL depth of 235.3 $\pm 64.9 \mu \mathrm{m}$ in patients undergoing CACXL with dextran containing riboflavin. ${ }^{16}$ In the present study where a HPMC containing, dextran free riboflavin formulation was used, the mean demarcation line depth measured on ASOCT in CACXL patients was approximately 60-70 $\mu \mathrm{m}$ deeper, i.e., $308.2 \pm 84.2 \mu \mathrm{m}$. Interestingly the TECXL group also had a mean demarcation line depth of 294.4 $\pm 57.1 \mu \mathrm{m}$ which was comparable to that of the CACXL group ( $p=0.66$ ) and that of standard 'epithelium-off' CXL. Variable depth of the demarcation line has been reported for TECXL ranging from as shallow as 90-125 $\mu \mathrm{m}$ to as deep as $250-316 \mu \mathrm{m}$.,19,22-24 A review of literature reveals that while studies reporting superficial demarcation lines with TECXL have used either the standard or only a slightly modified version of the Wollensak/Sieler ${ }^{1}$ protocol originally recommended for epithelium-off CXL, series in which deeper demarcation lines have been achieved after TECXL ${ }^{23,24}$ have involved significant modifications to enhance permeability of riboflavin across the intact epithelium including mechanical disruption of superficial epithelium, preoperative use of benzalkonium chloride-containing topical medications, a dextran free hypotonic riboflavin solution of higher $(0.5 \%)$ concentration, prolongation of the riboflavin-induction time to 45 minutes and use of iontophoresis. A deeper demarcation line in both groups of the present study, i.e., at $74.6 \%$ and $80 \%$ of the mean preoperative pachymetric value in the TECXL and CACXL groups respectively may be attributable to the use of HPMC containing, dextran free riboflavin. As opposed to dextran riboflavin, HPMC containing solutions have been shown to enhance stromal penetration of riboflavin. ${ }^{25}$ Experimental, ${ }^{26}$ and in vivo clinical studies ${ }^{27}$ have shown both a higher concentration of HPMC in the posterior stroma vis a vis dextran and deeper structural effects of HPMC riboflavin including keratocyte apoptosis up to pre-Descemetic levels. Despite the deeper demarcation line and borderline corneal thickness in both our groups, no endothelial damage was detected at the end of 6 months. Hagem et al. also did not note any detrimental effects on the endothelium. ${ }^{27}$ This endothelial protection may be secondary to the small but significant increase in corneal pachymetry (approximately $22 \mu \mathrm{m}$ and $35 \mu \mathrm{m}$ amongst the TECXL and CACXL groups, respectively) seen at the end of the initial 30-minute saturation phase with the HPMC containing riboflavin used in both groups of the present study, in addition to the protective effect of the riboflavin soaked contact lens in the CACXL group . Previous reports ${ }^{27,28}$ have also documented a $5-10 \%$ increased corneal thickness with the use of HPMC riboflavin, and this increase is likely to be predominantly seen in the loosely arranged posterior stroma lamellae as compared to the more compact anterior stroma.

TECXL has been suggested to be associated with less postoperative pain and decreased stromal haze as compared to standard epithelium-off CXL. ${ }^{9,18,20}$ However, in the present study, both pain and haze were comparable between the TECXL ('epithelium on' technique) and CACXL (a variant of the 'epithelium-off' technique) groups at all time points when they were measured. Additionally pain scores in the early postoperative period for the TECXL cohort in our study $(2.64 \pm 1.36$ on day 0 ; $1.36 \pm 1.12$ on day 1 ) were greater than those reported by Magli et al. ${ }^{18}$ for their TECXL cohort $(1.2 \pm 1.1$ on day $0 ; 0.9$ \pm 0.7 on day 1 ) in their study using the same parameter i.e. the Wong-Baker FACES pain rating scale. These outcomes may be attributable to the occurrence of epithelial defects/loose epithelium in a significant proportion of patients ( 5 of 11 eyes; $45.45 \%$ ) in the TECXL group on the first postoperative day in our study. Gatzioufas et al. ${ }^{29}$ also documented epithelial defects/loose epithelium in $69 \%$ of eyes undergoing TECXL with a riboflavin solution containing benzalkonium chloride. Pain and haze after CXL are related to the presence of an epithelial defect leading to the baring of the corneal nerves and exposure of the stroma to inflammatory mediators like prostaglandins and neuropeptides. Applying a BCL in the immediate postoperative period as done by Magli et al. ${ }^{18}$ or a two-stage protocol ${ }^{30}$ employing the sequential application of riboflavin with and without benzalkonium chloride may prevent the occurrence of epithelial defects in TECXL and hence improve patient comfort without compromising clinical outcomes.

Limitations of the present study include a small sample size in each group and a relatively short follow up. However, the prospective recruitment and randomization of eyes between groups ensured that comparisons were made in a homogenous subset of patients undergoing two different techniques.

\section{CONCLUSION}

Both TECXL and CACXL using HPMC riboflavin and UVA demonstrated an equal efficacy and safety in stabilizing progressive keratoconus in the short-term, in patients having borderline corneal thickness. A longer follows up with a larger patient base is, however, advisable to determine the stability of anatomical, biomechanical and functional indices with these techniques.

\section{CLINICAL SIGNIFICANCE}

Keratoconus patients with thin corneas, if denied the benefits of crosslinking due to the pachymetric restraints 
of conventional 'epithelium off' CXL may keep progressing to more advanced keratoconus and its associated complication, e.g., acute hydrops, inability to fit contact lenses, subepithelial scarring, etc., all of which can lead to a significant loss of BCVA and necessitate a corneal transplant. TECXL and CACXL, both simple and costeffective techniques appear to be efficacious and safe to arrest progression of ectasia in this subset of patients, and may reduce the need for future surgical interventions in these patients.

\section{REFERENCES}

1. Wollensak G, Spoerl E, Seiler T. Riboflavin/ultraviolet-Ainduced collagen crosslinking for the treatment of keratoconus. Am J Ophthalmol 2003;135(5):620-627.

2. Koller T, Mrochen M, Seiler T. Complication and failure rates after corneal crosslinking. J Cataract Refract Surg 2009;35(8):1358-1362.

3. Bottos KM, Schor P, Dreyfuss JL, et al. Effect of corneal epithelium on ultraviolet-A and riboflavin absorption. Arq Bras Oftalmol.2011;74(5):348-351.

4. Spoerl E, Mrochen M, Sliney D, et al. Safety of UVA-riboflavin crosslinkingof the cornea. Cornea 2007;26(4):385-389.

5. Hafezi F, Mrochen M, Iseli HP, et al. Collagen crosslinking with ultraviolet-A and hypoosmolar riboflavin solution in thin corneas. J Cataract Refract Surg 2009;35(4):621624.

6. Sachdev MS, Gupta D, Sachdev G, et al. Tailored stromal expansion with a refractive lenticule for crosslinking the ultrathin cornea. J Cataract Refract Surg 2015;41(5): 918-923.

7. Vinciguerra P, Randelman JB, Romano V, et al. Transepithelial iontophoresis corneal collagen cross linking for progressive keratoconus-initial clinical outcomes. J Refract Surg 2014; 30(11):746-753.

8. Leccisotti A, Islam T. Transepithelial corneal collagen crosslinking in Keratoconus. J Refract Surg 2010;26(12):942-948.

9. Filippello M, Stagni E, O'Brart D. Transepithelial corneal collagen crosslinking: bilateral study. J Cataract Refract Surg 2012;38(2):283-291.

10. Spadea L,Mencucci R. Transepithelial corneal collagen crosslinking in ultrathin Keratoconic corneas. Clinical Ophthalmology 2012;6:1785-1792.

11. Jacob S, Kumar DA, Agarwal A, et al. Contact Lens Assisted Collagen Cross-Linking (CACXL): A new technique for cross linking thin corneas. J Refract Surg 2014;30(6):366-372.

12. Wollensak G, Iomdina E. Biomechanical and histological changes after corneal crosslinking with and without epithelial debridement. J Cataract Refract Surg 2009;35(3): 540-546.

13. Greenstein SA, Fry KL, Bhatt J, et al. Natural history of corneal haze after collagen cross-linking for keratoconus and corneal ectasia: Scheimpflug and biomicroscopic analysis. J Cataract Refract Surg 2010;36(12):2105-2114.
14. Krumeich JH, Daniel J. Live epikeratophakia and deep lamellar keratoplasty for I-III stage-specific surgical treatment of keratoconus. Klin Monbl Augenheilkd 1997;211:94-100.

15. Wong D, Hockenberry MJ, Wilson D. Wong's Essentials of Pediatric Nursing, 8th edition. St. Louis: Mosby, 2009.

16. Malhotra C, Jain AK, Gupta A, et al. Demarcation line depth after contact lens-assisted corneal crosslinking for progressive keratoconus: Comparison of dextran-based and hydroxypropyl methylcellulose-based riboflavin solutions. J Cataract Refract Surg 2017;43(10):1263-1270.

17. Caporossi A, Mazzotta C, Paradiso AL, et al. Transepithelial corneal collagen crosslinking for progressive keratoconus:24monthclinical results. J Cataract Refract Surg 2013;39(8):11571163.

18. Magli A, Forte R, Tortori A, et al. Epithelium-off corneal collagen cross-linking versus transepithelial cross-linking for pediatric keratoconus. Cornea 2013;32(5):597-601.

19. Çerman E, Toker E, Ozcan DO. Transepithelial versus epithelium-off crosslinking in adults with progressive keratoconus. J Cataract Refract Surg 2015;41(7):1416-1425.

20. Rossi S, Orrico A, Santamaria C, et al. Standardversus transepithelial collagen cross-linking in keratoconus patients suitable forstandard collagen cross-linking. Clin Ophthalmol 2015;9:503-509.

21. Seiler T, Hafezi F. Corneal cross-linking-induced stromal demarcation line. Cornea 2006;25(9):1057-1059

22. Buzzonetti L, Petrocelli G. Transepithelial corneal crosslinking in pediatric patients:early results. J Refract Surg 2012;28(11):763-767.

23. Stojanovic A, Chen $\mathrm{X}$, Jin $\mathrm{N}$, et al. Safety andefficacy of epithelium-on corneal collagen cross-linking using a multifactorialapproach to achieve proper stromal riboflavin saturation. Journal of Ophthalmology 2012.

24. Bikbova G, Bikbov M. Transepithelial corneal collagen crosslinking by iontophoresisof riboflavin. Acta Ophthalmol 2014;92(1):e30-e34.

25. Waltman SR, Patrowicz TC. Effects of hydroxypropyl methylcellulose and polyvinyl alcohol on intraocular penetration of topical fluorescein in man. Invest Ophthalmol 1970; 9(12):966970.

26. Ehmke T, Seiler TG, Fischinger I, et al. Comparison of corneal riboflavin gradients using dextran and HPMC solutions. J Refract Surg 2016;32(12):798-802.

27. Hagem AM, Thorsrud A, Sandvik GF, et al. Collagen crosslinking with conventional and accelerated ultraviolet-A irradiation using riboflavin with hydroxypropyl methylcellulose. J Cataract Refract Surg 2017;43(4):511-517.

28. Wollensak G, Aurich H, Wirbelauer C, et al. Significance of the riboflavin film in corneal collagen crosslinking. J Cataract Refract Surg 2010;36(1):114-120.

29. Gatzioufas Z, Raiskup F, O'Brart D, et al. Transepithelial corneal cross-linking using an enhanced riboflavin solution. J Refract Surg 2016;32(6):372-377.

30. Muller D, Friedman M, Sherr E. Maximizing efficacy of accelerated transepithelial cross-linking. Avedro, http:// www.avedro.com/white-papers. 